\title{
Awareness of Vocabulary Learning Strategies among EFL Students in Khon Kaen University
}

\author{
Rakchanok Saengpakdeejit \\ The Faculty of Liberal Arts, Khon Kaen University, Nong Khai Campus, Nong Khai, Thailand
}

\begin{abstract}
In recent decades, vocabulary learning strategies have received increasing attention among language educators as they are found to facilitate foreign language learning. Limited vocabulary knowledge can be a crucial problem which leads the learners to encounter difficulties in language learning. In this study, types of vocabulary learning strategies used by Thai EFL students were examined. In order to identify the aforementioned group of students in terms of vocabulary learning strategy use, a semi-structured interview was used as a method of data collection. The participants were 63 undergraduate students studying at Khon Kaen University ( 2 campuses). Results of the study reveal that the students display awareness of vocabulary learning strategies. Two main types of vocabulary learning strategies were found: 1) strategies for discovering the meaning of unknown words; and 2) strategies for retaining the newly learned words in long-term memory and recalling them at will.
\end{abstract}

Index Terms - vocabulary learning strategies, language learning problems, second language learning

\section{INTRODUCTION}

Nowadays, it is undeniable that English has played an increasingly important role as the medium of communication among people from different countries; Thailand is no exception (Somsai \& Intaraprasert, 2011). Thus, English skills have become essential for Thai students as it is the global language for the dissemination of academic knowledge and it helps transform the educational experience of countless students (Akkakoson, 2012). Therefore, English is not only a subject studied in the classroom, but also a medium for social and practical use (Foley, 2005).

Thai students generally encounter problems or difficulties learning English, except those who attend international programs where English is used as the medium of instruction. Non-English major students also have less exposure to English than do students majoring in English. Despite a more or less regular use of the English language both inside and outside the classroom settings, they still encounter problems in their learning and they generally see the limitation of vocabulary knowledge as the first problem to overcome. According to Asgari and Mustapha (2011), this may be because vocabulary has been recognized as crucial to language use in which insufficient vocabulary knowledge of the learners led to difficulties in second language learning. Additionally, mastering vocabulary is one of the most challenging tasks that any learner faces while acquiring another language (Nyikos and Fan, 2007). Wilkins (1972) stated that without grammar, very little can be conveyed, without vocabulary, nothing can be conveyed. As far as the knowledge of vocabulary is concerned in language teaching and learning, it is a truism that vocabulary learning strategies are necessary. This is according to Soureshjani (2011), words are extremely important in language learning because they are the basic building blocks of language and they are the units of meaning from which the larger structures of language such as sentences, paragraphs, and whole texts are formed. Furthermore, various studies have shown that lexical problems frequently interfere with language learning. That is, language learning can be obstructed when learners lack vocabulary knowledge. Therefore, there is an increased interest in vocabulary as an important element of language learning.

Over the past few decades, it has been noticed that a number of researchers have shifted their interest from language teaching methods to language learning strategy use. This may be because some learners seem to be successful in language learning regardless of teaching methods (Soureshjani, 2011). Oxford (1990) stated that strategies are important for language learning because they are tools for active, self-directed involvement, which is essential for developing communicative competence (p.1). Then, it is undeniable that language learning strategies have played a vital role in second language learning, as they may assist learners in mastering the forms and functions required for reception and production of the second language and thus affect achievement (Soureshjani, 2011). If learners know more about effective learning strategies, they may use those strategies in their learning to enhance their effectiveness in language skills.

Thus, students need to be educated about vocabulary learning strategies. Therefore, vocabulary learning strategies have been brought to the language classroom. According to Dóczi (2011), vocabulary learning strategies are significant because the acquisition of vocabulary is a never-ending process and can solve insurmountable difficulties for language learners. It can be said that through the use of vocabulary learning strategies, learners may be able to maximize the effectiveness of their English language learning. On this basis, it is crucial to be aware of the basics of vocabulary 
learning strategies and how students adopt the strategies effectively. That is to say, it is vital to gain more insights into how Thai learners perceive the use of vocabulary learning strategies to help them learn vocabulary.

\section{LITERATURE REVIEW}

\section{A. The Meaning of 'Knowing a Word'}

What does 'knowing a word' mean? Does 'knowing a word' mean being able to recognize its written form and its meaning? This definition is insufficient. This is because it refers to only form and meaning, not all the other aspects of vocabulary knowledge. Vocabulary knowledge involves more than just the link between meaning and form, it is multifaceted (Laufer and Goldstein, 2004). This idea is consistent with that of Oxford and Crookall (1990) who indicate that 'knowing an L2 word' involves not just the ability to recognize the word or to match it with its L1 counterpart. Ling (2005) states that words are interwoven in a complex system in which knowledge of various levels of a lexical item is required in order to achieve adequate understanding in listening and reading or produce ideas successfully in speaking and writing.. According to Richards (1976), knowing a lexical item includes knowledge of word frequency, collocation, register, case relations, underlying forms, word association, and semantic structure. Alongside form and meaning, there is a distinction between receptive and productive knowledge that is used by researchers when investigating vocabulary learning (Milton, 2009). Nation (2001) also applies the terms 'receptive' and 'productive' to vocabulary knowledge description covering all the aspects of what is involved in knowing a word. Therefore, we can say that receptive and productive knowledge is another aspect which is useful in understanding the L2 vocabulary learning process.

\section{B. Vocabulary Learning Strategies (VLSs)}

Regarding a definition of vocabulary learning strategies, different researchers have defined VLSs differently. For example, Rubin (1987, p. 29) defines lexical strategies as "the process by which information is obtained, stored, retrieved, and used." Takač (2008, p. 52) explains that VLSs are "specific strategies utilized in the isolated task of learning vocabulary in the target language." Further, Catalán (2003, p. 56) sees VLSs as "knowledge about the mechanisms (process, strategies) used in order to learn vocabulary as well as steps or actions taken by students (a) to find out the meaning of unknown words, (b) to retain them in long-term memory, (c) to recall them at will, and (d) to use them in oral or written mode." In addition, Asgari and Mustapha (2011, p.85) have defined VLSs as 'steps taken by the language learners to acquire new English words." Thus, it can be said that VLSs are commonly used not only to discover the meanings of unknown words but also to retain them in long-term memory and to recall them at will. For the present investigation, the term 'vocabulary learning strategies' has been defined as 'an attempt or attempts made by language learners while encountering vocabulary problems to discover the meanings of unknown words, to retain the newly learned words in long-term memory and to recall them at will.'

\section{Taxonomies of Vocabulary Learning Strategies}

VVLs are commonly used by the L2 learners in language class. Currently, a lot of empirical studies based mostly on learners' self-report of their vocabulary learning strategies use are found. Among those studies, there have been attempts to develop taxonomies of vocabulary learning strategies. In classifying learning strategies, scholars have different ways of classifying them (Intaraprasert, 2000). These classification systems give a crucial contribution to lexical knowledge. On the whole, the classifications proposed by Rubin and Thompson (1994), Gu and Johnson (1996), Lawson and Hogben (1996), Schmitt (1977), and Nation (2001) are often cited in the studies on vocabulary learning strategies. The following are some examples of vocabulary learning strategies classifications which have been classified differently according to the principles of terminology and categorization of different researchers. There is a wide-ranging inventory of vocabulary learning strategies developed by Schmitt in 1977. His taxonomy falls into two main groups of strategies: discovery strategies and consolidation strategies. There are two strategy categories emerging in the first group: determination strategies and social strategies. The latter comprises social strategies, memory strategies, cognitive strategies, and metacognitive strategies. Rubin and Thompson (1994) introduced three main categories of vocabulary learning strategies that have been reported by language learners to be effective. They are Direct Approach, Mnemonics, and Indirect Approach. In addition, there is another accepted classification as suggested by Lawson and Hogben (1996). They classified vocabulary learning strategies based on the information obtained through the think-aloud method and interviews provided by 15 university students learning Italian in Australia. The fifteen strategies were classified under four categories: repetition, word feature analysis, simple elaboration, and complex elaboration. Nation's classification (2001) is another one which is frequently cited in the literature on vocabulary learning strategies. Nation (2001) identified three main categories of strategies-planning, sources, and processes, each covering a subset of strategies. 'Planning' involves choosing what and when to focus attention on the vocabulary items. This category contains strategies for choosing words, choosing the aspects of word knowledge, choosing strategies, and planning repetition. 'Sources' refers to finding information about words from analyzing the words; context, dictionary, etc. 'Process' means establishing lexical knowledge through such powerful processes as noticing, retrieving and generating. One of the most prominent classifications is developed by Gu and Johnson (1996). $\mathrm{Gu}$ and Johnson (1996) developed a 91-item VLS questionnaire which can be divided into groups-metacognitive 
regulation, cognitive strategies, memory strategies, and activation strategies. The first one makes the meaning of vocabulary items clear through the use of a variety of means. Guessing, use of dictionary, and note-taking are grouped as cognitive strategies. Rehearsal and encoding are instances of memory strategies. Finally, activation strategies include the strategies through which learners actually use new words in different contexts.

The aforesaid vocabulary learning strategy classifications have been classified by different researchers based mostly on the results of their studies. However, exactly the same vocabulary learning strategy classifications cannot be found. This means that there is no exact agreement for vocabulary learning strategy classification. Additionally, some problems, such as a limit of English background knowledge, a fear of criticism and a feeling of shyness for making mistakes, or a lack of chance to be in an English environment, may cause the learners to use different strategies. The researcher believes that an awareness of vocabulary learning strategies can provide a basis for assisting learners in language learning. Accordingly, the present study aims to explore what strategies are employed by the students to deal with their language learning.

\section{METHODOLOGY}

\section{A. Participant}

A total of 63 undergraduate students studying at Khon Kaen University (2 campuses) were selected through the purposive sampling method on the basis of convenience and availability. At the time of data collection, the participants were enrolled in at least one English course. Within this group, there were 33 science-oriented students and 30 non science-oriented students. Their ages ranged from 18 to 22 .

\section{B. Data Collection}

To investigate the students' awareness of reading strategy use, one-to-one semi-structured interviews which were carried out in Thai were conducted as the main method of data collection. Prior to the actual stage of data collection, the interview questions were pilot with the Khon Kaen University students in order to check whether or not the questions worked properly, or if there was anything wrong with the wording, question sequences, timing, and so on (Intaraprasert, 2000). After that, the questions were rechecked and refined. The interview was conducted after each English class was finished (henceforth it can be called the 'post-class interview'). There were two main parts in the interview. The first part of the interview (Questions 1 to 4) was concerned with gathering basic information about the interviewees. The second part (Questions 5 to 13) focused on the students' vocabulary learning strategies employed both inside and outside a language classroom. The main purposes of post-class interview were to determine whether students were consciously aware of the specific vocabulary learning strategies they employed while studying, and how they solved problems associated with unfamiliar vocabulary. All interviews were recorded. The following shows the question concept used in the present investigation.

Part I:

Q1: an introduction part of the interviews, including the interviewer's and interviewee's names, the interviewee's field of study, and the purposes of the interview;

Q2: an investigation of the number of English courses each interviewee is studying, or has already studied;

Q3: an investigation of each interviewee's perception of his/her English language ability

Q4: an investigation of each interviewee's opinion about the importance of English in his/her life, and future career;

Part II:

Q5: an investigation of each interviewee's opinion about what he/she finds difficult in learning English and how he/she solves the problems;

Q6: an investigation of each interviewee's opinion on what aspects are necessary for learning English (If the interviewee's answer is that vocabulary is necessary, the interviewer will ask the next question. If the answer is not about vocabulary, the interviewer will stop this interview.)

Q10: an investigation of each interviewee's opinion on what aspects of problems he/she has in learning vocabulary items;

Q11: an investigation of the interviewee's purposes on employing vocabulary learning strategies

Q 12: an investigation of the interviewee's use of vocabulary learning strategies to discover the meanings of new English vocabulary items

Q13: an investigation of each interviewee as to what vocabulary learning strategies he/she employs to recall newlylearned English vocabulary items

\section{Data Analysis}

After completing the stage of data collection, the interview recordings were transcribed verbatim. Then, the transcribed data were translated from Thai into English for the purpose of data analysis. The translated data were crosschecked for the accuracy by two Thai lecturers and one English native speaking lecturer teaching English at the university. The transcribed data were then analyzed with 'open and axial coding' techniques proposed by Punch (2005) and Strauss and Corbin (1998). The data were carefully read for possible codes and categories relevant to the purpose of the study. The stage of data analysis could be summarized as follows. 
1. Looking through the interview data obtained from the 63 students in order to see the overall picture of what they reported doing to deal with their learning in terms of vocabulary.

2. Looking at interview data script in detail, and making a list of statements which can be seen as vocabulary learning strategies. 1,541 statements eventually emerged.

3. Grouping all these 1,541 statements based on the similarities of the context or situation in which the vocabulary learning strategies were reported being employed for English learning. Then, these reported statements were categorized based on the purpose to be achieved. At this stage, the reported statements were initially classified into 64 main groups.

4. Identifying those 64 groups. It was not easy to merge each strategy use into a suitable group and to find the suitable name to cover most because some reported strategies seemed to overlap with others.

5. After some intensive revisions, the researcher had to make a clear distinction between vocabulary learning strategies and other types of strategies. Consequently, 33 groups of the reported statements were deleted because they were not consistent with the definition of vocabulary learning strategies for the present study.

6. Reconsidering and reclassifying the 31 remaining strategy groups under two main purposes to be achieved which are 1) strategies employed to discover the meaning of unknown words; and 2) strategies employed to retain the newly learned words in long-term memory and to recall them at will. At this stage, some individual strategy items were excluded because they were inconsistent with the proposed definition. For some other strategies which shared similar characteristics, they were merged. Eventually, 37 individual strategy items categorized into 6 categories under two main purposes remained.

\section{RESULT}

Based on the results of the data analysis, the 37 individual emergent strategies for dealing with language learning in terms of vocabulary were classified by purposes to be achieved: 1) strategies for discovering the meaning of unknown words; and 2) strategies for retaining the newly learned words in long-term memory and recalling them at will. The former make the meaning of unknown vocabulary items clear through the use of strategies. They were further categorized into 3 categories: 1.1) Discovery Strategies (DS); 1.2) Social Strategies (SoS); and 1.3) Support Strategies (SuS). The latter allow the learners to memorize the newly learnt words in the long term, and be able to recall them anytime. They were categorized into 3 categories: 2.1) Memory Strategies (MS); 2.2) Cognitive Strategies; and 2.3) Metacoginitive Strategies. Figure 1 below illustrates the complete vocabulary learning strategy classification found from the stage of the data analysis.

\begin{tabular}{|l|l|l|}
\hline \multirow{2}{*}{$\begin{array}{c}\text { Vocabulary Learning } \\
\text { Strategies }\end{array}$} & Strategies for discovering the meaning of unknown words & Discovery Strategies \\
\cline { 3 - 3 } & & Social Strategies \\
\cline { 2 - 3 } & $\begin{array}{l}\text { Strategies for retaining the newly learned words in long- } \\
\text { term memory and recalling them at will }\end{array}$ & Memory Strategies \\
\cline { 3 - 3 } & & Cognitive Strategies \\
\hline
\end{tabular}

Figure1: A Classification of Vocabulary Learning Strategy

\section{Purpose 1: Strategies for discovering the meaning of unknown words}

Strategies for discovering the meaning of unknown words are the strategies that the students reported employing to get the meaning of unfamiliar or unknown vocabulary items with or without any helps. This purpose includes a variety of different strategies. And they are divided into three main categories as follows:

Category 1: Discovery Strategies (DS)

The strategies under this category aim to help learners to discover the meaning of words by themselves without any assistance from anyone or anything. There are altogether eight strategies in this category. These strategies include:

DS 1: Guess the meaning from the context

DS 2: Guess the meaning of the new words by analyzing the part of speech of them such as noun, verb, adjective, adverb

DS 3: Guess the meaning from the grammatical structure of sentence

DS 4: Guess the meaning of the new words by analyzing the affixes and roots of them

DS 5: Guess the meaning of the new words from aural features, such as stress, pronunciation

DS 6: Guess the meaning of the new words from real situations

DS 7: Guess the meaning of the new words from gestures

DS 8: Guess the meaning of the new words from some available pictures, graphs, figures, etc.

\section{Category 2: Social Strategies (SoS)}

The strategies under this category aim to help learners to discover the meaning of words by interacting with someone, such as peers, classmates, teachers, etc. In using the strategies in this category, the student was likely to consult someone expected to be able to explain the meanings of unfamiliar or unknown vocabulary items. Eventually, he/she could get the meaning of those vocabulary items. The emergent strategies in this category include:

SoS 1: Ask classmates and friends for the meaning of the words

SoS 2: Ask teachers for the meaning of the words 
SoS 3: Ask other people, such as members of one's family or native speakers of English for the meaning of the words Category 3: Support Strategies (SuS)

The strategies under this category aim to aid learners in discovering the meanings of new words by using some support mechanisms such as a dictionary. The students likely to consult some support equipment expected to help them with the meaning of unknown words. The strategies under this category include:

SuS 1: Use an English-English dictionary

SuS 2: Use an English-Thai dictionary

SuS 3: Looking up the meaning of a new vocabulary item from electronic resources e.g. talking dictionary, dictionary program in a computer, and the Internet

SuS 4: Use websites in the internet, such as Google

Purpose 2: Strategies employed to retain the newly learned words in long-term memory and to recall them at will

Category 4: Memory Strategies (MS)

The strategies under this category aim to aid learners in learning the new words through mental process by linking their existing knowledge with the new words. There are altogether nine strategies in this category. These strategies include:

MS 1:Link the word to a Thai word with similar sound

MS 2:Try to use newly learned words in conversation with friends and teachers

MS 3:Try to use newly learned words in imaginary situations in one's mind

MS 4:Use words and concept associations

MS 5:Link the words to visual images

MS 6:Make up one's own sentences using the newly learned words

MS 7:Link the words to other English words with similar sound

MS 8:Link the words to other English words with similar spelling

MS 9: Link the words to one's own experience

\section{Category 5: Cognitive Strategies (CS)}

The strategies under this category are the procedures the learners employ while learning intended to help the learners to retain the newly learned words in long-term memory and to recall them at will. The strategies under this category include:

CS 1: Say the word with its meaning repeatedly

CS 2: Write newly learned words items with meanings on papers and stick them on the wall in one's bedroom and repeatedly spell the words

CS 3: Make a vocabulary list with meanings and examples in a notebook

CS 4: Label English words on physical objects

CS 5: Use word cards

Category 6: Metacoginitive Strategies (MetS)

The strategies under this category are carefully planned techniques intended to help the learners to retain the newly learned words in long-term memory and to recall them at will. The strategies under this category include:

MetS 1: remember words by doing English exercises after class

MetS 2: remember words by grouping newly learned words according to the similarity of pronunciation and spelling

MetS 3: remember words by grouping newly learned words according to the synonyms and antonyms

MetS 4: remember words by doing dictations.

MetS 5: remember words by playing crossword puzzles and scrabble

MetS 6: remember words by watching an English-speaking film with subtitles

MetS 7: remember words by reading novels, newspapers, short stories, magazines, something from the internet, etc.

MetS 8: remember words by listening to English songs

\section{DISCUSSION}

The main purpose of the present study was to investigate how Khon Kaen University students deal with language learning in terms of unknown words. The findings from the interview demonstrated that the students are well aware of different vocabulary learning strategies. In summary, this study has arrived at the result that the vocabulary learning strategy classification emerging from the interview is consistent with some classifications classified by other scholars. For example, the classification from this study was similar to that from Schmitt's taxonomy (1997).

Moreover, the findings show various emergent strategies were reported to be employed to cope with language learning problems in terms of unknown words. In this situation, the students relied on different strategies to handle the problems. What follows is a discussion of certain strategies to deal with their vocabulary learning problems.

'Using a dictionary" and 'guessing from the context' were common strategies which were reported to be employed by all 63 research subjects, when they encountered vocabulary difficulties. These strategies are under categorization of Support Strategies and Discovery Strategies respectively. This finding is consistent with that of Asgari and Mustapha (2011) who found that among the Malaysian students, both 'using a monolingual dictionary' and 'guessing from the 
context' has been mentioned as common strategies which have been employed in vocabulary learning situations. The popularity of these two strategies may be because the use of a dictionary and guessing from context clues are common practice in language class for second/foreign language learners. Furthermore, a dictionary gives detailed guidance on pronunciation, grammar and usage with explanations written in controlled, simplified vocabulary (Asgari and Mustapha. 2011). Carter (1987) also added that a dictionary provides examples of words used in various contexts as well. This finding is also in agreement with the findings of $\mathrm{Wu}$ (2005) which showed the common use of electronic dictionary strategy among Taiwanese students. In addition, in English language classes in Thai situation, most of the time, teachers encourage students to consult their dictionaries for the meanings of unknown words. Therefore, we can say that 'using a dictionary" and 'guessing from the context' are likely to be significant for language learners to employ when they encounter some sort of vocabulary learning problems for better language learning results.

'Watching an English-speaking film' and 'listening to English songs' were other reported strategies by a few students to remember newly learnt words. The use of films and songs in this study is consistent with the results of the study conducted by Asgari and Mustapha (2011) which showed that using the English-language media such as songs, movies, TV programs, etc. were reported to be used frequently by Malaysian students. Asgari and Mustapha (2011) point out that authentic materials are good in terms of learning new words in their context. Moreover, a possible explanation of this finding may relate to the convenient accessibility of the new technology. That is to say, students may be able to maximize their English learning practice opportunities through media.

Regarding 'reading novels, newspapers, short stories, magazines, or something from internet, etc', this finding is in agreement with the findings of a number of studies which have shown that second language learners acquire vocabulary through reading (Haggan, 1990; Asgari and Mustapha, 2011; Pigada and Schmitt, 2006; Yali, 2010). Pigada and Schmitt (2006) found that an extensive reading program can enhance lexical knowledge, words spelling, meaning, and grammatical knowledge. According to Yamamoto (2011), extensive reading can promote the incidental learning lof L1 and L2 receptive vocabulary. Additionally, Dóczi (2011, p.142) states that "Reading stands out as one of the most important sources of language input, perhaps because this is the most traditional way of expanding vocabulary". A possible explanation for this finding may relate to the traditional Thai educational system whereby in English language classroom, teachers have usually used English newspapers as a teaching method to improve and assist the learning and acquisition of vocabulary. This finding is also consistent with that of Haggan (1990) who found that the use of newspapers in EFL classes is a successful language method.

With regard to the strategies of learning new words through the mental process, "trying to use newly learned words in conversation with friends and teachers" emerged from this study. The students showed that they applied new English words in their daily speaking. Four of them mentioned that they practiced new words among their friends and tried to ask the teacher questions about the English lesson in the classroom. To explain this emergence, it is necessary to define the term 'knowing a word'. If 'knowing a word' means the ability to recognize it (form) and to use it (meaning) correctly, the productive and receptive vocabulary knowledge may explain this emergence. Then, a possible explanation for this finding might be that the receptive and productive knowledge of vocabulary learning affects the amount of vocabulary gained. It can be said that a number of new words can be learned receptively through listening, and productively through speaking. Shahov (2012) states that receptive knowledge is being able to understand a word in its spoken form and productive knowledge means to be able to use a word correctly in speech. However, word knowledge is not only form and meaning. It is multifaceted because it involves more than just the link between meaning and form (Laufer and Goldstein, 2004). Although speaking practice can help learners expand their vocabulary, it cannot be the totality of vocabulary learning. Therefore, we can say that the relation between the ability in producing speech and lexical knowledge is very complex and still unclear.

'Linking the words to visual images' was another strategy which was reported to be frequently employed by the research subjects. This finding is consistent with that of Siriwan (2007) who found that in the Thai Rajabhat university students context, 'words and pictures associations' was also reportedly used by the students to help them link new words and visual symbols. Oxford and Crookall (1990, p. 16) states that "Visual image is a very useful aid for learning L2 vocabulary. The use of visual imagery for vocabulary learning is based on making associations between a picture and a word. The theory on which this technique is founded is that most learners are capable of associating new information to concepts in memory by means of meaningful visual images, and that visual images make learning more efficient." Therefore, visual imagery is likely to be significant for language learners to employ when they encounter some sort of vocabulary learning problems.

\section{CONCLUSION}

The main objective of the study was to examine types of vocabulary learning strategies employed by Thai EFL students. Lexical knowledge is very important for improving students' English proficiency, but learners normally feel a lot of anxiety about their vocabulary learning because of its difficulty. Both language teachers and learners should be aware of how important vocabulary learning strategies are in their language learning. In this study, many strategies have been reportedly employed by the research subjects. That is, the findings of the study have several pedagogical implications in the field of foreign language teaching for the tertiary level of education, particularly for teachers and learners. Raising awareness of vocabulary learning strategies may assist the learners to overcome their vocabulary 
learning problems. The ability to use appropriate VLSs in a more efficient way is a useful skill that the students require. In sum, raising awareness of EFL students of the vocabulary learning problems, and of the advantages for employing different VLSs to overcome those problems should be included as a part of the teaching process.

\section{ACKNOWLEDGMENT}

I would like to thank Khonkaen University, Nong Khai Campus, Thailand for supporting the fund for doing this research. In addition, I would like to thank the editor and the reviewers of this journal for their comments.

\section{REFERENCES}

[1] Akkakoson, S. (2012). Raising Strategic Awareness of Thai EFL Students of Science and Technology Disciplines through Metacognitive Strategy Training. The Southeast Asian Journal of English Language Studies 18.4, 35-47.

[2] Asgari, A., \& Mustapha, A.B. (2011). The Type of Vocabulary Learning Strategies Used by ESL Students in University Putra Malaysia. English Language Teaching 4.2, 84-90.

[3] Carter, R. (1987). Vocabulary and Second/Foreign Language Teaching. Language Teaching 20.1, 3-16.

[4] Catalán, R.M.J. (2003). Sex Differences in L2 Vocabulary Learning Strategies. International Journal of Applied Linguistics 13.1, 54-77.

[5] Dóczi, B. (2011) Comparing the Vocabulary Learning Strategies of High School and University Students: A Pilot Study. WoPaLP 5, 138-158.

[6] Foley, J.A. (2005). English in Thailand. RELC Journal 36.2, 223-234.

[7] Gu, P. Y. (1994). Vocabulary Learning Strategies of Good and Poor Chinese EFL Learners. Paper presented at the Annual Meeting of the Teachers of English to Speakers of Other Languages (p.27). Baltimore, March.

[8] Gu, P.Y., \& Johnson, R.K. (1996). Vocabulary Learning Strategies and Language Learning Outcomes. Language Learning 46, 643-679.

[9] Haggan, M. (1990). Hitting the Headlines. English Teaching Forum 28, 41-42.

[10] Intaraprasert, C. (2000). Language Learning Strategies employed by Engineering Students Learning English at the Tertiary Level in Thailand. Ph.D Thesis, The University of Leeds, Leeds, England.

[11] Intaraprasert, C. (2006). Beliefs about Learning English by Thai and Vietnamese EST Students: A Cross-Cultural Perspective. Paper presented at The 2006 TEFL International Conference "Spreading Our Wings: Meeting TEFL Challenges". Fukuoka, Japan, August.

[12] Laufer, B., \& Goldstein, Z. (2004). Testing Vocabulary Knowledge: Size, Strength, and Computer Adaptiveness. Language Learning 54, 399-436.

[13] Lawson, M.J., \& Hogben, D. (1996). The Vocabulary-Learning Strategies of Foreign-Language Students. Language Learning 46.1, 101-135.

[14] Ling, L.Y. (2005). Teaching Vocabulary Learning Strategies: Awareness, Beliefs, and Practices. A Survey of Taiwanese EFL Senior High School Teachers. MA Thesis, The University of Essex, Essex, England.

[15] Milton, J. (2009). Measuring Second Language Vocabulary Acquisition. Clevedon: Multilingual Matters.

[16] Nation, I.S.P. (2001). Learning Vocabulary in Another Language. Cambridge: Cambridge University Press.

[17] Nyikos, M., \& Fan, M. (2007). A Review of Vocabulary Learning Strategies: Focus on Language Proficiency and Learner Voice. In Mizumoto, A., \& Takeuchi, O. (2009). Examining the Effectiveness of Explicit Instruction of Vocabulary Learning Strategies with Japanese EFL University Students. Language Teaching Research 13.4, 425-449.

[18] Oxford, R. (1990). Language Learning Strategies: What Every Teacher should know. Boston: Newbury House.

[19] Oxford, R., \& Crookall, D. (1990). Vocabulary Learning: A Critical Analysis of Techniques. TESL Canada Journal 7.2, 9-30.

[20] Pigada, M., \& Schmitt, N. (2006). Vocabulary Acquisition from Extensive Reading: A Case Study. Reading in a Foreign Language 18.1, 1-28.

[21] Punch, K.F. (2005). Introduction to Social Research (2nd ed.). London: SAGE Publications Ltd.

[22] Richards, J.C. (1976). The Role of Vocabulary Teaching. TESOL Quarterly 10.1, 77-89.

[23] Rubin, J. (1987). Learner Strategies: Theoretical Assumptions, Research History and Typology. In A. Wenden \& J. Rubin (eds.), Learner Strategies in Language Learning . New York: Prentice Hall, 29-42.

[24] Rubin, J., \& Thompson, I. (1994). How to be a More Successful Language Learner (2 ${ }^{\text {nd }}$ ed.). Boston: Heinle.

[25] Schmitt, N. (1997). Vocabulary Learning Strategies. In N. Schmitt \& P. McCarthy (eds), Vocabulary:Description, Acquisition and Pedagogy. Cambridge: Cambridge University Press, 199-228

[26] Shahov, V.P. (2012). Measuring L2 Receptive and Productive Vocabulary Knowledge. University of Reading: Language Studies Working Papers 4, 37-45.

[27] Siriwan, M. (2007). English Vocabulary Learning Strategies Employed by Rajabhat University Students. Ph.D Thesis, Suranaree University of Technology, Nakhon Ratchasima, Thailand.

[28] Somsai, S., \& Intaraprasert, C. (2011). Strategies for Coping with Face-to-Face Oral Communication Problems Employed by

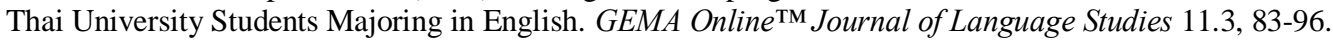

[29] Soureshjani, K.H. (2011). Gender-oriented Use of Vocabulary Strategies: A Comparative Study. Theory and Practice in Language Studies 1.7, 898-902.

[30] Strauss, A., \& Corbin, J. (1998). Basic of Quantitative Research: Techniques and Procedures for Developing Ground Theory. $\left(2^{\text {nd }}\right.$ ed.). Thousand Oaks, California: SAGE Publishers.

[31] Takač, V. P. (2008). Vocabulary Learning Strategies and Second Language Acquisition. Clevedon: Multilingual Matters.

[32] Wilkins, D.A. (1972). Linguistics and language teaching. London: Edward Arnold.

[33] Wu, W. (2005). Use and Helpfulness Rankings of Vocabulary Learning Strategies Employed by EFL Learners in Taiwan. Journal of Humanities and Social Sciences 1.2, 7-13. 
[34] Yali, G. (2010). L2 Vocabulary Acquisition Through Reading — Incidental Learning and Intentional Learning. Chinese Journal of Applied Linguistic 33.1, 74-93.

[35] Yamamoto, Y. (2011). Bridging the Gap between Receptive and Productive Vocabulary Size through Extensive Reading. The Reading Matrix 11.3, 226-242.

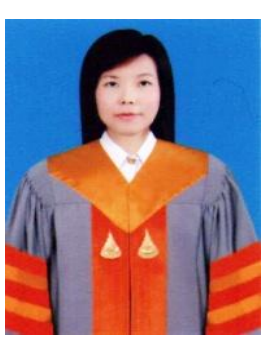

Rakchanok Saengpakdeejit (Ph.D.) is an assistant professor in TESOL at Khonkaen University, Nong Khai Campus, Thailand. She has been taught English courses at different institutions in Thailand for more than 10 years. Her main research interests are language learning strategies, reading strategies, and vocabulary learning strategies. 